\title{
Agranulocytosis Associated with Trandolapril-Verapamil Combination
}

\author{
Mustafa Genco Erdem ${ }^{1}$, Ahmet Eskiocak ${ }^{2}$, Osman Yokus ${ }^{3}$, Habip Gedik ${ }^{4 *}$
}

${ }^{1}$ Hamur State Hospital, Internal Medicine Clinic, Turkey

${ }^{2}$ Ankara University, Faculty of Medicine Anesthesiology and ICM Department, Turkey

${ }^{3}$ Department of Hematology, Ministry of Health Istanbul Training and Research Hospital, Turkey

${ }^{4}$ Department of Infectious diseases and Clinical Microbiology, Ministry of Health Bakırkoy Sadi Konuk Training and Research Hospital, Turkey

*Corresponding author: Habip Gedik, Associate Professor, Department of Infectious diseases and Clinical Microbiology, Ministry of Health Bakırkoy Sadi Konuk Training and Research Hospital, Turkey, Tel: + 90212414 72 02/ 5315; E-mail: habipgedik@gmail.com

\begin{abstract}
A number of medications have been implicated as potential causes of severe neutropenia or agranulocytosis. A 66-year-old female patient was administered with verapamil-trandolapril for treatment of hypertension. Over three years of verapamil-trandolapril treatment, neutropenia developed. Verapamil-trandolapril was switched to amlodipine and white blood cell count recovered within two months. After a while, amlodipine was switched to ramipril because of the pretibial edema (a side effect of amlodipine); over thirty days neutropenia developed once again. Agranulocytosis is rarely seen due to angiotensin converting enzyme (ACE) inhibitors. Therefore, physicians should be aware of the potential side effects of ACE inhibitors and their combinations on blood cells (especially neutrophils), particularly in patients treated for a long time.
\end{abstract}

Keywords: ACE inhibitor; Agranulocytosis; Drug induced neutropenia; Neutropenia; Ramipril; Trandolapril; Verapamil
Received Date: November 20, 2015

Accepted Date: January 6, 2016

Published Date: January 9, 2016

Citation: Gedik, H., et al. Agranulocytosis Associated with Trandolapril-Verapamil Combination (2016) Int J Hematol Therap 2(1): 1-3.

\section{Introduction and General Information}

Neutropenia is defined as a decline in the neutrophil count to a level below 500/ $\mu$, which generally occurs after chemotherapy or radiotherapy ${ }^{[1]}$, and as it is predicted to develop, it is treated with G-CSF therapy ${ }^{[2-4]}$. Neutropenia may also be induced by analgesic/anti-inflammatory drugs ${ }^{[5-8]}$ angiotensin converting enzyme (ACE) inhibitors ${ }^{[9-12]}$, antipsychotics, oral antidiabetics and antithyroid drugs. Several clinical cases of agranulocytosis, neutropenia or neutropenic fever, induced by various drugs, have been reported in the literature in the form of case reports or case series. In this case report, we present a case developing agranulocytosis induced by trandolapril-verapamil combination, as well as the relevant therapeutic approach, aiming to draw attention to a rare side effect of this commonly used drug and raise awareness.

\section{Case Report}

A 66-year-old woman with diabetes mellitus and hypertension presented to our internal medicine outpatient clinic with the complaints of fever and dysphagia. The patient's body temperature was measured as $37.9^{\circ} \mathrm{C}$ and her complete blood cell count $(\mathrm{CBCC})$ revealed the leukocyte count of $880 / \mu \mathrm{L}$ (neutrophil $10 / \mu \mathrm{L}$ ), hemoglobin $12.3 \mathrm{~g} / \mathrm{dl}$, hematocrit $36.5 \%$, and platelet count $292,000 / \mu \mathrm{L}$. The patient was receiving "verapamil-trandolapril" combination for hypertension for about three years, along with subcutaneous insulin for diabetes mellitus. The evaluation of her peripheral blood smear by a hematology specialist was associated with a "suspicious" blast-like cell, and a bone marrow biopsy was performed. Bone marrow aspiration biopsy specimen showed 
a marked increase in myeloid-granulocyte series, an $\mathrm{M} / \mathrm{E}$ ratio around 2/1, normal erythroid series and cellular proliferation in lymphoid series, normal megakaryocytes both in number and degree of maturation, with no atypical blastic cells. Thus, findings suggested a toxic agent. In addition, it confirmed that the patient had no benign or malignant myelodysplastic or infiltrative disease. Patient's previous CBCC results were revealing that her absolute neutrophil count had gradually declined over the years (September 2011: 2000/ $\mu \mathrm{L}$, January 2012: 1200/ $\mu \mathrm{L}$, November 2012: 800/ $\mu \mathrm{L}$ ). The serological tests for the etiology of agranulocytosis, as well as autoantibodies test and four blood cultures taken from the patient, resulted in negative, while the results of the measurements for thyroid functions, vitamin B12 and folate levels were also within normal range. The thorax CT scan detected no significant pathology and her echocardiography findings were normal. As trandolapril, the active ingredient in the verapamil-trandolapril combination used by the patient is known to cause agranulocytosis as a side effect and none of the other drugs she had been using had been reported to cause agranulocytosis as a side effect. The drug was discontinued and a therapy with "amlodipine" $10 \mathrm{mg}$ once daily was started. The patient also had a tinea pedis infection, which was successfully treated with a topical anti-fungal therapy. During the hospitalization period, the patient's body temperature never rose above $36.9^{\circ} \mathrm{C}$, while her neutrophil levels began to improve gradually after the discontinuation of the drug containing trandolapril, which we considered the cause of neutropenia. About a week later, her neutrophil count increased to a level of $370 / \mu \mathrm{L}$. She was discharged with a healthy condition. CBCC on the day 20 after the discontinuation of drug showed a leukocyte value of $4300 / \mathrm{mm} 3$ and a neutrophil count of $2000 / \mu \mathrm{L}$. The CBCC at day 50 after the discontinuation of the drug showed that leukocyte level was $4350 / \mathrm{mm} 3$ and neutrophil count $2260 / \mu \mathrm{L}$, and then the patient's follow-up was continued. Three months after the discharge, she once again presented to the emergency department with a complaint of swollen feet. The swelling of the feet was associated with the amlodipine therapy, and thus amlodipine was discontinued. After the initiation of the treatment with ramipril $5 \mathrm{mg} /$ day, the patient's neutrophil count declined once again to a level of $1100 / \mu \mathrm{L}$. Considering that ramipril might also cause agranulocytosis, the patient's antihypertensive treatment was administered as nifedipine $60 \mathrm{mg} /$ day. In the follow-up, CBCC of the patient showed no significant decline in leukocyte and neutrophil values.

\section{Discussion and Conclusion}

A neutrophil count below $1500 / \mu \mathrm{L}$ in the $\mathrm{CBCC}$ during 1-3 weeks of follow-up after the drug use and the absence of additional pathologies that may cause neutropenia suggest a diagnosis of drug-induced neutropenia. Fever is generally the first symptom of the drug-induced neutropenia ${ }^{[13]}$. ACE inhibitors, which are used for the treatment of congestive heart failure and hypertension, have been reported to cause neutropenia as a side effect, though rarely. The most commonly reported cases in the literature mainly include neutropenia cases induced by captopril ${ }^{[9-12,14-15]}$, with some cases associated with the use of enalapril $^{[16]}$ and ramipril ${ }^{[17]}$.

There are two basic mechanisms in drug-induced neutropenia and/or agranulocytosis ${ }^{[18-22]}$ :
- Immune-mediated destruction of neutrophils by the circulating antibodies induced or stimulated by drugs

- The direct toxic effect of the drug on the granulocytic precursors in the bone marrow

In our case, a gradual decline occurred in the neutrophil count during the use of trandolapril, an ACE inhibitor, whereas an improvement was observed in the neutrophil count following the discontinuation of the drug. The neutrophil count that recovered after the discontinuation of trandolapril decreased again below the level of $1500 / \mu \mathrm{L}$ after the patient began to use ramipril (another ACE inhibitor) three months later. That suggests that the neutropenia side effect of those drugs could actually be a class effect. The bone marrow aspiration smear, which was performed at the time of diagnosis, showed a significant reduction in the myeloid series. That indicates that the drug metabolites have a toxic effect on myeloid-granulocyte series, the precursors of neutrophil series, and reduce the production. Therefore, the main cause of neutropenia is not the destruction in the periphery, but such reduction in the production of bone marrow is due to the toxic effect of the drug.

The specific risk factors for agranulocytosis might include the following:

- Advanced age ( $>50$ years $)^{[23]}$

- Female gender $(70 \% \text { of the cases are women })^{[24-25]}$

- A history of infectious mononucleosis ${ }^{[26]}$

- Chronic renal failure in patients using captopril or insufficient urinary excretion of the drug in patients receiving concomitant probenecid ${ }^{[27]}$

- Therapy with a combination of ACE inhibitors and interferon (particularly high risk) ${ }^{[28]}$

- The presence of underlying autoimmune disease ${ }^{[29]}$

As can be seen, our patient's gender (female) and advanced age (66 years) were among the factors that predisposed to development of agranulocytosis.

After the initiation of drugs known to cause neutropenia, $\mathrm{CBCC}$, and peripheral smear examinations should be performed at regular intervals during the first three months for an earlier diagnosis. Still, long-term use of those drugs should be avoided in patients with autoimmune diseases, such as systemic lupus erythematosus and systemic sclerosis, since such patients are at higher risk of developing neutropenia ${ }^{[29]}$.

In the cases of drug-induced neutropenia, the main treatment principle is the discontinuation of the drug. The previous studies reported that the neutrophil count normalized within 3 to 56 days after the drug was discontinued ${ }^{[30-32]}$. The diagnosis is confirmed by the increasing neutrophil count following the discontinuation of the drug. If a low neutrophil count is accompanied by a clinical infection and fever, blood samples, urine and throat cultures should be immediately obtained and a broad-spectrum antibiotic therapy should be initiated ${ }^{[33]}$. If there is a marked decrease in the neutrophil count (below $500 / \mu \mathrm{L}$ ), an additional therapy with granulocyte-colony stimulating factor (filgrastim or lenograstim $5 \mathrm{mcg} / \mathrm{kg} /$ day) may be administered subcutaneously or intravenously (for about 5-7 days) until the neutrophil count increases over $1500 / \mu \mathrm{L}^{[34-38]}$.

In our case, such cultures were obtained and there was no growth. With a healthy condition, the patient was discharged at day 7 with scheduled outpatient follow-up visits. Her neutrophil count was measured as $2000 / \mu \mathrm{L}$ at day 20 after the discon- 
tinuation of drug.

In conclusion, neutropenia or profound neutropenia (called agranulocytosis if neutrophil count is below 500/ $\mu \mathrm{L}$ )[39] may occur within 5-7 days, or even later, following the use of any drug. This case report aims to draw attention to neutropenia that develops through a toxic effect on the myeloid-granulocyte series induced by verapamil-trandolapril, a combination of anti-hypertensive agents commonly used for the treatment of hypertension, which is one of the most common diseases in today's world the discontinuation of the drug and the use of neutrophil-stimulating cytokines, as well as an appropriate antibiotic therapy for infections in the presence of fever provide a near-complete clinical and laboratory recovery within 3-5 days in such cases.

\section{References}

1. Crawford, J., Dale, D.C., Lyman, G.H. Chemotherapy-induced neutropenia: risks, consequences, and new directions for its management. (2004) Cancer 100(2): 228-237.

2. Lyman, G.H. Risks and consequences of chemotherapy-induced neutropenia. (2006) Clin Cornerstone 8(Suppl 5): S12-8.

3. Dale, D. Current management of chemotherapy-induced neutropenia: the role of colony-stimulating factors. (2003) Semin Oncol 30(Suppl 13): 3-9.

4. Dale, D.C. Colony-stimulating factors for the management of neutropenia in cancer patients. (2002) Drugs 62 Suppl 1: 1-15.

5. Strom, B.L., Carson, J.L., Schinnar, R., et al. Nonsteroidal anti-inflammatory drugs and neutropenia. (1993) Arch Intern Med 153(18): 2119-2124.

6. Rodman, M.J., Hurley, M.L. Risk of NSAID-related neutropenia adds up to a small number of cases. (1994) RN 57(5): 82.

7. Kalksma, R., Jansen, A., Bruyn, G.A.W. Severe neutropenia due to naproxen therapy in rheumatoid arthritis: a case report and review of literature. (2002) Neth J Med 60(7): 289-291.

8. Handa, S.I., Freestone, S. Mefenamic acid-induced neutropenia and renal failure in elderly females with hypothyroidism. (1990) Postgrad Med J 66: 557-559.

9. DiBianco, R. Adverse reactions with angiotensin converting enzyme inhibitors. (1986) Med Toxicol 1(1): 122-141.

10. Cooper, R.A. Captopril-associated neutropenia. Who is at risk? (1983) Arch Intern Med 143(4): 659-660.

11. Brown, N.J., Vaughan, D.E. Cardiovascular Drugs. Angiotensin-Converting Enzyme Inhibitors. (1998) Circulation 97(14): 14111420.

12. Edwards, I.R., Coulter, D.M., Beasley, D.M., et al. Captopril: 4 years of post marketing surveillance of all patients in New Zealand. (1987) Br J Clin Pharmacol. 23(5): 529-536.

13. Andres, E., Maloisel, F. Idiosyncratic drug-induced agranulocytosis or acute neutropenia. (2008) Curr Opin Hematol 15: 15-21.

14. Gleason, M.M., Roloff, J.S., Cyran, S.E., et al. Captopril-induced bone marrow suppression in two cardiac patients with trisomy 21 . (1993) Pediatr Cardiol 14(4): 227-229.

15. Young, T.H., Lin, S.H., Ko, W.S., et al. Captopril-induced agranulocytosis: a case report. (1993) Chinese Medical Journal (Taipei) 51(2): 151-153.

16. Elis, A., Lishner, M., Lang, R., et al. Agranulocytosis associated with enalapril. (1991) DICP 25(5): 461-462

17. Horowitz, N., Molnar, M., Levy, Y., et al. Ramipril-Induced Agranulocytosis Confirmed by a Lymphocyte Cytotoxicity Test. (2005) Am J Med Sci 329(1): 52-53.

18. Tesfa, D., Keisu, M., Palmblad, J. Idiosyncratic drug-induced agranulocytosis: possible mechanisms and management. (2009) Am J Hematol 84(7): 428-434.
19. Uetrecht, J.P. Current trends in drug-induced autoimmunity. (1997) Toxicology119(1): 37-43.

20. Uetrecht, J.P. Myeloperoxidase as a generator of drug free radicals. (1995) Biochem Soc Symp 61: 163-170.

21. Uetrecht, J.P. Idiosyncratic drug reactions: possible role of reactive metabolites generated by leukocytes. (1989) Pharm Res 6(4): 265-273. 22. Ju, C., Uetrecht, J.P. Oxidation of a metabolite of indomethacin (Desmethyldeschlorobenzoylindomethacin) to reactive intermediates by activated neutrophils, hypochlorous acid, and the myeloperoxidase system. (1998) Drug Metab Dispos 26(7): 676.

23. Kaufman, D.W., Kelly, J.P., Levy, M., et al. Drug etiology of agranulocytosis: Update of the International Agranulocytosis and Aplastic Anemia Study. (1993) Pharmacoepidem Drug Safety 2: S25-S29.

24. Kantero, I., Mustala, O.O., Palva, I.P. Drug-induced agranulocytosis, with special reference to aminophenazone. IV. Children. (1972) Acta Med Scand 192(4): 327-330.

25. Alvir, J.M., Lieberman, J.A., Safferman, A.Z., et al. Clozapine-induced agranulocytosis. Incidence and risk factors in the United States. (1993) N Engl J Med 329(3): 162-167.

26. Levy, M., Kelly, J.P., Kaufman, D.W., et al. Risk of agranulocytosis and aplastic anemia in relation to history of infectious mononucleosis: a report from the international agranulocytosis and aplastic anemia study. (1993) Ann Hematol 67(4): 187-190.

27. Sinhvi, S.M., Duchin, K.L., Willard, D.A., et al. Renal handling of captopril: effect of probenecid. (1982) Clin Pharmacol Ther 32(2):182189.

28. Casato, M., Pucillo, L.P., Leoni, M., et al. Granulocytopenia after combined therapy with interferon and angiotensin-converting enzyme inhibitors: evidence for a synergistic hematologic toxicity. (1995) Am J Med 99(4): 386-391.

29. Parish, R.C., Miller, L.J. Adverse effects of angiotensin converting enzyme (ACE) inhibitors. An update. (1992) Drug Safe 7(1): 14-31.

30. Jacobson, I.M., Kelsey, P.B., Blyden, G.T., et al. Sulfasalazine-induced agranulocytosis. (1985) Am J Gastroenterol 80(2): 118-121.

31. Heit, W., Heimpel, H., Fischer, A., et al. Drug-induced agranulocytosis: evidence for the commitment of bone marrow haematopoiesis. (1985) Scand J Haematol 35(5): 459-468.

32. Meyer-Gessner, M., Benker, G., Lederbogen, S., et al. Antithyroid drug-induced agranulocytosis: clinical experience with ten patients treated at one institution and review of the literature. (1994) J Endocrinol Invest 17(1): 29.

33. Freifeld, A.G., Bow, E.J., Sepkowitz, K.A., et al. Clinical practice guideline for the use of antimicrobial agents in neutropenic patients with cancer: 2010 update by the infectious diseases society of america. (2011) Clin Infect Dis 52(4): e56-93.

34. Young, N.S. Agranulocytosis. (1994) JAMA 271(12): 935-938.

35. Andres, E., Maloisel, F., Zimmer, J. The role of haematopoietic growth factors granulocyte colony-stimulating factor and granulocyte-macrophage colony-stimulating factor in the management of drug-induced agranulocytosis. (2010) Br J Haematol 150(1): 3-8.

36. Tajiri, J., Noguchi, S., Murakami, N. Usefulness of granulocyte count measurement four hours after injection of granulocyte colony-stimulating factor for detecting recovery from antithyroid drug-induced granulocytopenia. (1997) Thyroid 7(4): 575-578.

37. Fathallah, N., Slim, R., Rached, S., et al. Sulfasalazine-induced DRESS and severe agranulocytosis successfully treated by granulocyte colony-stimulating factor. (2015) Int J Clin Pharm 37(4): 563-565.

38. Mossad, S.B. Agranulocytosis induced by nonchemotherapy drugs. (2008) Ann Intern Med 148(4): 320-321.

39. Andersohn, F., Konzen, C., Garbe, E. Systematic review: agranulocytosis induced by nonchemotherapy drugs. (2007) Ann Intern Med 146(9): 657-665. 